\title{
Article
}

\section{Delayed and differential effects of the economic crisis in Sweden in the 1990s on health-related exclusion from the labour market: A health equity assessment}

Burstrom, Bo, Nylen, Lotta, Barr, Ben, Clayton, Stephen, Holland, Paula and Whitehead, Margaret

Available at http://clok.uclan.ac.uk/10672/

Burstrom, Bo, Nylen, Lotta, Barr, Ben, Clayton, Stephen ORCID: 0000-00032823-1495, Holland, Paula and Whitehead, Margaret (2012) Delayed and differential effects of the economic crisis in Sweden in the 1990s on healthrelated exclusion from the labour market: $A$ health equity assessment. Social Science \& Medicine, 75 (12). pp. 2431-2436.

It is advisable to refer to the publisher's version if you intend to cite from the work.

For more information about UCLan's research in this area go to

http://www.uclan.ac.uk/researchgroups/ and search for <name of research Group>.

For information about Research generally at UCLan please go to http://www.uclan.ac.uk/research/

All outputs in CLoK are protected by Intellectual Property Rights law, including Copyright law. Copyright, IPR and Moral Rights for the works on this site are retained by the individual authors and/or other copyright owners. Terms and conditions for use of this material are defined in the policies page. 
Short report

\title{
Delayed and differential effects of the economic crisis in Sweden in the 1990s on health-related exclusion from the labour market: A health equity assessment
}

\author{
B. Burström ${ }^{\mathrm{a}, *}$, L. Nylén ${ }^{\mathrm{a}}$, B. Barr ${ }^{\mathrm{b}}$, S. Clayton ${ }^{\mathrm{b}}$, P. Holland ${ }^{\mathrm{c}}$, M. Whitehead ${ }^{\mathrm{b}}$ \\ ${ }^{a}$ Karolinska Institutet, Department of Public Health Sciences, Division of Social Medicine, Norrbacka building, SE-171 76 Stockholm, Sweden \\ ${ }^{\mathrm{b}}$ Department of Public Health and Policy, University of Liverpool, Liverpool L69 3GB, UK \\ ${ }^{\mathrm{c}}$ Division of Health Research, Lancaster University, UK
}

\section{A R T I C L E I N F O}

Article history:

Available online 27 September 2012

Keywords:

Health inequalities

Economic crisis

Differential consequences

Sweden

\begin{abstract}
A B S T R A C T
Many OECD countries are currently experiencing economic crisis and introducing counter-measures with unknown effects. To learn from previous experience, we explored whether there were delayed or differential effects of the Swedish recession in the 1990s and the government's response to it for people with limiting longstanding illness or disability (LLSI) from different socioeconomic groups (SEGs), by policy analysis and secondary data analysis of the Swedish Survey of Living Conditions (ULF) from 1978 to 2005. The government policy response involved cutting public expenditure, privatising some services and measures to boost private sector employment. There was a decline in overall employment rates from the early 1990s, particularly among men and women with LLSI and in lower SEGs. Public sector employment declined from 53 to 40 percent among women and from 23 to 14 percent among men. Private sector employment increased modestly for women (from 31 percent to 37 percent), and stayed stable at 59-60 percent among men. Following economic recovery, employment rates continued to decline among men and women with LLSI from manual SEGs, while the employment levels increased among most healthy men and women. There was a concomitant increase in rates of LLSI, sickness absence and rates of disability pension particularly among women in lower SEGs.

Conclusion: The policy response to the 1990s economic crisis in Sweden had differential consequences, hitting the employment of women in the public sector, especially women with both LLSI and low socioeconomic status. The observed increase in disability pension rates, particularly among women with LLSI in lower SEGs, may be a delayed effect of the policy response to the economic crisis.
\end{abstract}

(c) 2012 Elsevier Ltd. All rights reserved.

\section{Background}

Many OECD countries are currently experiencing economic crisis and introducing counter-measures which may affect some groups in the population more than others, such as people with limiting longstanding illness or disability (LLSI). There is intense speculation about the possible adverse health effects of policies to deal with the crisis, but any long-term effects will not be known for several years (Stuckler, Basu, \& McKee, 2010). The purpose of this paper is to learn from previous experiences by examining the Swedish experience of the 1990s recession and the government's response to it from a health equity perspective. Specifically, we assess whether there were delayed or differential effects on people with LLSI from different socioeconomic groups (SEGs).

\footnotetext{
* Corresponding author.

E-mail address: bo.burstrom@ki.se (B. Burström).
}

Welfare states and public health outcomes

While there has been a long tradition in political science of studying the characteristics of welfare states, epitomised by Esping-Andersen's seminal work (Esping-Andersen, 1990), the emerging literature linking different types of welfare state or system to public health outcomes is relatively recent. Conceptual models of the social determinants of health emphasise the role played by socioeconomic political context in shaping the public policies that in turn influence access to essential resources for health (CSDH, 2008; Dahlgren \& Whitehead, 2007), and how differential access to those resources, along with differential susceptibility and differential consequences, may be important mechanisms generating health inequalities (Diderichsen, Evans, \& Whitehead, 2001).

Empirical evidence on welfare states and public health outcomes indicates potentially important linkages (Beckfield \& Krieger, 2009; Eikemo, Bambra, Judge, \& Ringdal, 2008; Navarro 
et al., 2006). A recent systematic review found that social democratic regimes (including Sweden, Norway and Denmark) tended to fare best in terms of absolute health outcomes but the evidence was inconsistent in terms of relative health inequalities (Muntaner et al., 2011). Another systematic review of the impact on health inequalities of politics and policies concluded that the transition to a capitalist economic and neoliberal restructuring probably increase health inequalities; the type of welfare state is inconsistently related to health inequalities (Beckfield \& Krieger, 2009).

The existing ecological studies raise further conceptual issues, not least the fundamental question of "what is it about welfare states that affect the health and longevity among their populations and that also vary systematically across different types of welfare state?" (Lundberg, 2008, p. 1105). Lundberg maintains that the resources available to people are of paramount importance for the levels of health and health inequalities in a country - including the resources generated through the welfare state. This emphasises the importance of analysing the consequences for different population groups of specific welfare state policies of relevance to their lives, not just the principles on which the welfare states are based (Lundberg, Åberg Yngwe, et al., 2008).

Studying differential consequences by social position also requires analysis of individual level data, rather than ecological data, integrated with analysis of relevant policy. Comparing the fate of people with and without LLSI on the labour market, we found evidence of differential employment consequences by social class, but that these inequalities were smaller in the Nordic countries than in Britain and Canada, due to differences in active labour market policies as well as the wider labour market policy context (Holland, Burström, et al., 2011; Holland, Nylen, et al., 2011).

\section{Effect of the economic crisis and policy response on health}

From a public health perspective, it is important to disentangle the effects of economic crisis as such from the effects of the specific policy responses to that crisis. Stuckler, Basu, Suhrcke Coutts, and McKee (2009) investigated how economic changes had affected mortality rates over three decades from 1970 to 2007 in 26 EU countries. Rises in unemployment during economic downturns were associated with significant short-term increases in premature deaths from suicide, while traffic fatalities were reduced. Importantly, when countries invested more than 200 Euro per capita in active labour market programmes and family support programmes, rising unemployment rates had no significant impact on suicides. From a further historical analysis on OECD countries, Stuckler et al. (2010) argue that safeguarding welfare spending during economic recession is important for population health, showing a strong correlation of higher social welfare spending with lower rates of cardiovascular disease and alcohol-related mortality that was not observed for healthcare spending.

Previous studies of the effects of the economic crisis in Sweden have concluded that the effects on health and health inequalities were moderate, possibly due to the buffering effects of the extensive Swedish welfare state (Lundberg, Diderichsen, \& Åberg Yngwe, 2001). There was, however, an increase from the mid-1990s in the rates of people reporting less than good self-rated health, anxiety and sleep disorders, particularly among women. Lone mothers, young adults and recent immigrants were harder hit by the economic crisis (Fritzell, Ringbäck Weitoft, Fritzell, \& Burström, 2007; Palme et al., 2003). These studies did not assess delayed effects.

Effects may also be on other health-related outcomes such as attachment to the labour market, and may differ between different SEGs. A Norwegian study (van der Wel, Dahl, \& Birkelund, 2010) of employment 1980-2005 among those with chronic illness, did not find a relation to business cycles, but rather that postindustrial labour market developments contributed to lower employment over time in this group.

In a changing labour market, demands from employers for flexibility and qualifications among employees may increase, rendering some groups less attractive on the labour market, such as people with a health condition limiting their work capacity. Analysis of longer-term trends using people with LLSI as tracers may shed further light on the mechanisms leading to differential consequences.

\section{Methods}

We reviewed policy documents, national and OECD statistics to identify the nature and extent of the economic crisis and the Swedish government's policy response over the period from early 1990s to 2005.

\section{Secondary data analysis}

We carried out secondary analysis of the Swedish Survey of Living Conditions (ULF) from 1978 to 2005 of trends in rates of employment and disability pension by LLSI, sex and SEG, with a total sample of 105,882 individuals in the working age-range of 25-59 years.

\section{Variables}

Limiting longstanding illness (LLSI) was defined as reporting any long-standing health problem (disability, injury or disease) that restricted work ability or daily activity. Those who did not report LLSI were categorised as 'healthy'.

\section{Socioeconomic group}

Socioeconomic group (SEG) was derived from occupation classified according to the Statistics Sweden classification (1982), grouped into four categories.

\section{Statistical analysis}

Age-standardised prevalence rates of LLSI, employment, and disability pension, standardised to the European standard population. Analyses were stratified by sex, age, SEG, year and timeperiod (based on the prevailing labour market situation). Three year moving averages were calculated. All analyses used SAS (version 9.1).

The study was approved by the Regional Ethical Review Board in Stockholm (dnr 2008/1004-32).

\section{Results}

\section{Sweden during the $1990 \mathrm{~s}$}

The economic crisis, with negative growth in Gross National Product during 1991-1993, resulted in a decline of employment by more than half a million people and unemployment rose from 1.7 to $8.3 \%$. This severely strained state finances, through reduced income taxes and increased public expenditure on unemployment benefits (Lundberg et al., 2001). The high unemployment levels dropped slightly from 1998 onwards, but the unemployment rate remained elevated at or above $5 \%$ in the first years of the 21 st century. In the wake of the economic recession, market forces became more dominant than before in the Swedish labour market (Wikman, 2001). Many workplaces disappeared, and the workload increased on those remaining in work.

The central government's policy response to the crisis included diverse measures and varied over time and with political 
leadership. In addition, local government (county councils and municipalities) in Sweden has their own parliaments and taxation rights and hence contributed to the multitude of policy changes that were initiated in response to the crisis. Furthermore, a tax reform added to the impact of the crisis and several other reforms governing the relation between central and local government took place during the 1990s (Palme et al., 2003). Initially, fighting inflation was prioritised and budgets were cut back. Government expenditure as percent of GDP increased from 60.1 in 1990 to 70.9 in 1993 (OECD, 2010).

Subsequent actions at central level aimed to keep welfare services intact and to increase employment. State subsidies to local government also aimed to secure welfare services. However, with reduced tax revenues, public sector jobs were still cut back. The number of employees in the local government sector declined from nearly 1.3 million to less than 1.1 million from 1990 to 1998 (Palme et al., 2003), which hit women in particular, as their employment was highly concentrated in the public sector (Fig. 1). For many years public sector employment was high in Sweden particularly among women in the local government sector, constituting almost one third of the work force, providing care for children and the elderly, in health services and schools (Hort, 2009). Such jobs were part of a deliberate welfare strategy, both to provide women with jobs, but also to enable other women to take up employment outside the home, both of which have contributed to historically high female employment rates in Sweden (Esping-Andersen, 1990). From 1997 onwards, other efforts of reconstitution were made, e.g. an Adult Education Initiative for 100,000 people and initiatives to reduce unemployment among young adults (Palme et al., 2003).

At the same time publicly financed but privately provided services increased in all local government welfare service sectors such as child care, schools, old-age care (Palme et al., 2003). The decline in public sector employment of women from 1992 was not fully matched by a corresponding increase in their private sector employment. For men, public sector employment declined, but from a much lower base than for women (Fig. 1).

During the 1990s market-oriented practices became more common in both privately and publicly provided welfare services. The government also increased user fees for health and social services. In child care and compulsory schooling, resources were depleted - staff frequency and costs per child declined while children's groups increased in size. Income maintenance systems were restricted in eligibility and benefit levels (Palme et al., 2003).

\section{Differential decline in employment by LLSI and SEG}

Overall employment rates were at a maximum level at the end of the 1980s, though always lower for people with LLSI than for the healthy (Fig. 2, Web Table 1a and b). Just before the economic recession at the beginning of the 1990s, employment rates were $78 \%$ for women with LLSI and $93 \%$ for healthy women. These rates dropped to $62 \%$ and $85 \%$ respectively during the recession. Healthy men showed a stable employment rate of $97 \%$ from the end of the 1970 s to the early 1990 s and dropped to $89 \%$ in 1993 . The employment rate of men with LLSI went from a high of $88 \%$ at the end of 1980 s to $75 \%$ by 1995 (and continuing down) (Fig. 2, Web Table 1a).

Following economic recovery, employment rates continued to decline among men and women with LLSI from manual SEGs (Web Table 1a). Over the same period, the employment levels increased among healthy men and women in all but the higher non-manual male group. For healthy women in all but the lower non-manual group, not only did employment rates increase, but by 20002005 they exceeded those in the pre-crisis period.

\section{Increase in prevalence of LLSI by SEG}

The proportions of women reporting LLSI increased significantly during the study period (Web Table 2), across all groups but particularly among unskilled manual women. The overall rate of LLSI among women went from $19.6 \%$ in $1978-1989$ to $23.7 \%$ in 2000-2005 (17.1\% in 1978-1989 and 18.1\% in 2000-2005 for men). However, the socioeconomic gradient was similar among men and women across time. Whilst the prevalence of LLSI had been increasing in the 1980s, this rate accelerated following the economic crisis.

\section{Sickness absence rise}

Sickness absence amongst people in work, particularly among women, started increasing in 1998 and peaked in 2003, before declining to mid-crisis levels by 2005 (Fig. 3).

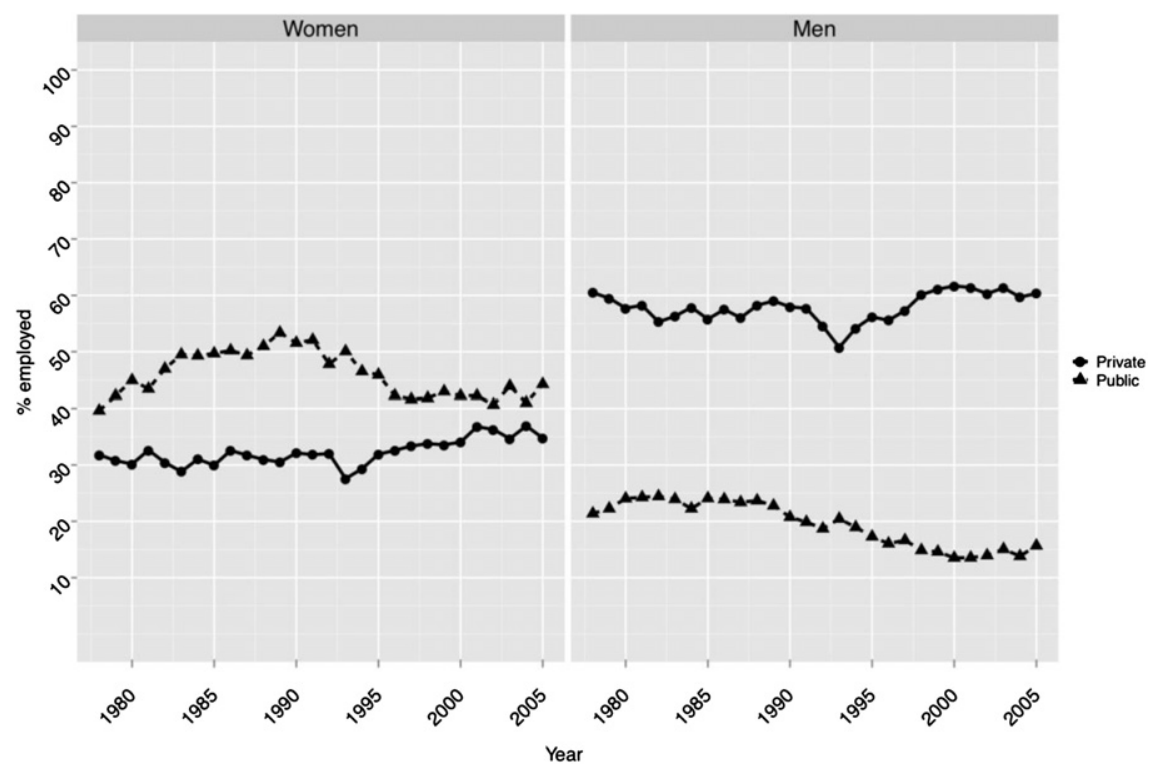

Fig. 1. Proportion of women and men employed in the public and private sectors in Sweden, 1978-2005. 


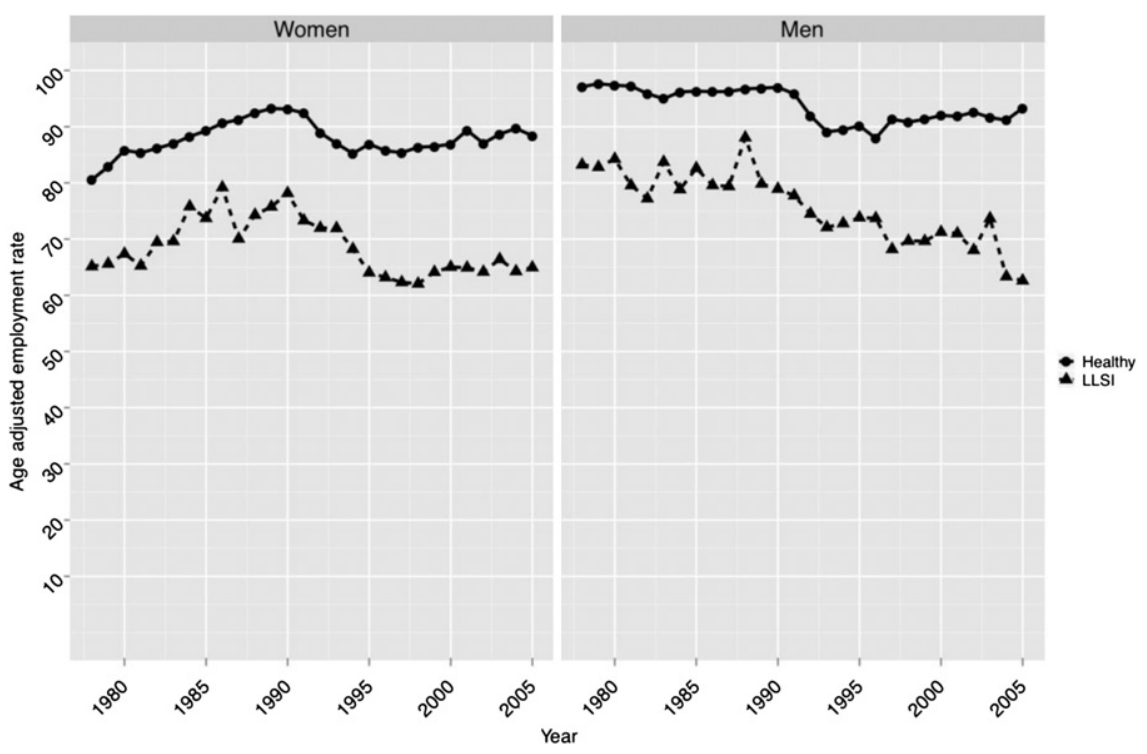

Fig. 2. Age adjusted employment rates for men and women in Sweden, 1978-2005.

\section{Trends in disability pension by gender and SEG}

The rates of disability pension among persons with LLSI increased from 1978-1989 to 2000-2005 in all socioeconomic groups, but unskilled manual women had the greatest increase over time (10 percentage points) (Fig. 4, Web Table 3). The rates of disability pension also increased significantly among higher nonmanual women, but from lower levels. Whilst the level of disability pensions among women with LLSI in the unskilled manual group was increasing slowly pre-crisis, the economic crisis appeared to accelerate this trend for this SEG (Fig. 4). For women in other SEGs, the disability pension rate showed a fluctuating or even declining trend in the 1980s, but then an increase during the 1990s, which was very rapid for lower non-manual women from the early to mid-1990s. The pattern for men in different SEGs was less consistent. Unskilled manual men showed an immediate rise in disability pension rates at the onset of the recession, similar to that seen for unskilled manual women. The rate for skilled manual men, however, flattened out in the early 1990s, before rising markedly from 1995 to 2000. Rates for lower non-manual men fluctuated considerably from 1985 to 2005, while rates for higher non-manual men were low and stable from 1980 to 2000, when they rose

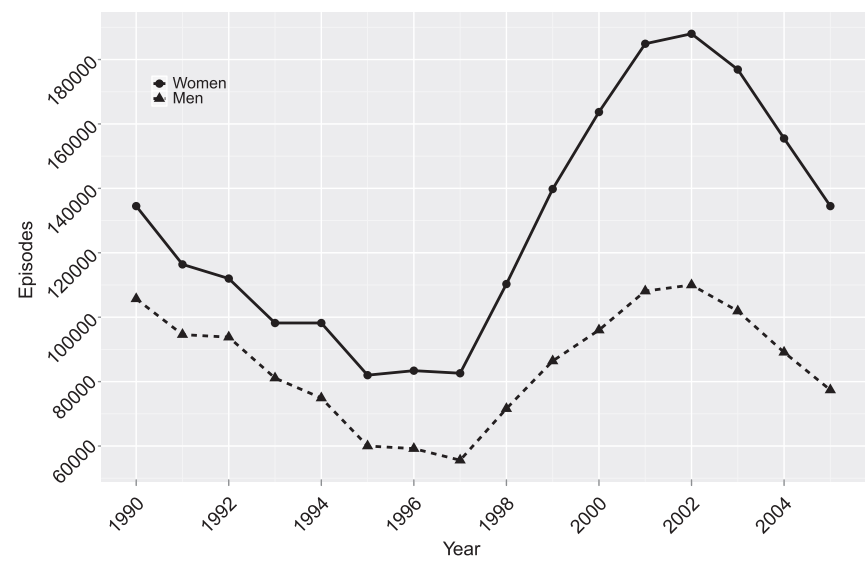

Fig. 3. Sickness absence (number of on-going episodes) among women and men, 1990-2005. markedly (Fig. 4). From 1997 onwards, the rates of disability pension among women exceeded those among men, particularly among unskilled manual groups. The socioeconomic gradient in the rates of disability pension varied somewhat over time but was of a similar magnitude at the beginning and end of the study period.

\section{Discussion}

In the early 1990s the unemployment rates increased to levels unseen in Sweden since the 1930s, declined somewhat towards the end of the 1990s but remained at or above $5 \%$ in the period 2000 2005. During the 1990 s, some 700,000 jobs were lost. Rates of disability pension increased throughout the period, particularly among female unskilled manual workers with LLSI.

The partial reversal of the high rates of female employment in the local government sector meant that there were some noticeable differences in how the economic crisis affected women as compared to men in Sweden. The loss of women's jobs was almost entirely from the public sector. A significant number of these women who lost their jobs in the public sector will have had LLSI. The increase in the proportion of women both out of work and having an LLSI, that occurred as a result of these job losses, represents about $3-5 \%$ of the female working age population. Our hypothesis is that this is partly responsible for the increase in the numbers of women from manual SEGs who moved onto disability pensions a few years later. In addition, due to the strain in public finances, the burden of work increased among employees remaining at work (Palme et al., 2003). This greater strain on those remaining at work may also have generated further disability pensions in this group. Clearly it is difficult to determine causality, because of the cross-sectional nature of the data analysed and the time lag between women becoming unemployed and moving onto a disability pension. It is likely that the transition from job loss to a disability pension takes place through multiple stages over a few years, for example through periods of unemployment and/or sickness absence.

Throughout the 1990s, there were also considerable changes to the Swedish social insurance system in eligibility and benefit levels (Palme et al., 2003), which may have contributed to the development. One study compared two cohorts of employees on long-term sickness absence and their return to work at the beginning of the 


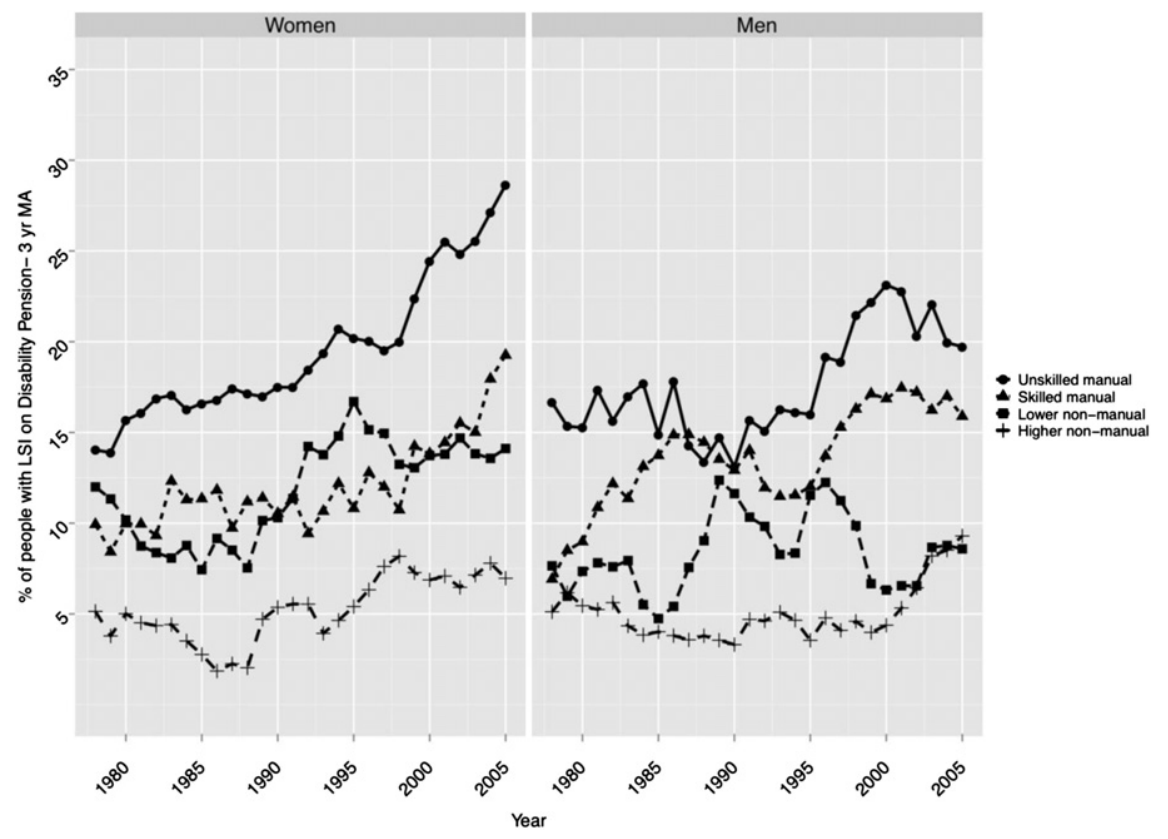

Fig. 4. Age adjusted disability pension rates for women and men in Sweden by SEG, 3 year moving average, 1978-2005.

1990s and 2000s (Hetzler, Melén, \& Bjerstedt, 2005). The length of sickness absence increased in the second cohort, as did rehabilitation back to work and the number of disability pensions awarded also increased. This exclusion from the labour market was differential and particularly common among the older, the unemployed and among women, in jobs with low education qualifications and with lower incomes. Unemployment was an intermediate step towards disability pension, particularly among women. Psychiatric diagnoses (particularly depression) were more common among the unemployed who received disability pension (Hetzler et al., 2005). The increase in disability pension rates probably partly reflects the increase in morbidity, and in that sense disability pension is a positive social safety net providing economic security for those who cannot earn their living. On the other hand, the differential pattern indicates that some groups were more affected than others.

Clearly there are also other processes influencing the pattern of health related exclusion from the labour market observed in our study. The changes in the labour market also meant that fewer unskilled jobs remained for people with lower educational qualifications or with limitations to their work capacity (Wikman, 2001). The proportion of jobs classified as blue collar declined from 47 to 42\% from 1989 to 1999, while jobs classified as white collar increased from 44 to $49 \%$ (Marklund \& Wikman, 2001). This is similar to the postindustrial developments observed in Norway (van der Wel et al., 2010). In addition, more insecure forms of employment such as temporary contracts, increased during the 1990s (Wikman, 2001). Other studies have indicated a worsening of psychosocial working conditions during the 1990s (Rostila, 2008), due in part to reduced investments in the work environment and in part to the increase in the proportion of persons with insecure attachment to the labour market.

These changes in the work environment may have had an effect on health and may in part explain the increase in the prevalence of LLSI amongst women identified in our study. These may also make it harder for people with health problems to stay in work. Psychiatric complaints, including stress, exhaustion and tiredness, increased after the mid-1990s (Marklund \& Wikman, 2001). A study comparing risk factors for long-term sickness absence in 1986-89 and in 2002 found that in 2002 women had a higher risk of long-term sickness absence and psychosocial work environment and job situations were of greater importance (Lidwall, Bergendorff, Voss, \& Marklund, 2009).

Active labour market interventions (ALMPs) in terms of investments in longer-term educational efforts were common previously, but were reduced. In spite of economic improvement and an economic boom after the 1990s, levels of unemployment remained considerably higher than previously. Nevertheless, Sweden has remained a comprehensive welfare state in terms of social and health insurance and economic security (Palme et al., 2003). The female labour force participation rate peaked at the end of the 1980s but is still very high in Sweden by international standards. Despite the crisis, employment rates among people with LLSI also remained high compared to levels in other countries (Holland, Burström, et al., 2011; Holland, Nylen, et al., 2011). This is a major achievement of the Swedish welfare state and raises the counterfactual question of how much worse the situation might have been for people in a vulnerable position on the labour market without such a strong system to support them.

The findings of our study indicate that there may be detrimental consequences from government actions to reduce public expenditure in response to economic crisis. One of the long-term consequences of Sweden's deficit reduction plan in the 1990s appears to have been the increase in women receiving disability pensions from the late 1990s to 2005. In Finland, which also experienced a severe economic crisis in the early 1990s, there was initially less emphasis on ALMPs than in Sweden, but such policies increased over time (SOU, 2000). ALMPs can be used to help protect the unemployed against the detrimental effects of unemployment (HAPI, 2012).

How and when to reduce budget deficits is currently a major issue for many countries in Europe and North America, in particular the part to be played by cuts to public services as opposed to tax rises. Whilst there has been much debate about the economic consequences of deficit reduction, recent analyses has indicated the effects of reductions in health and social expenditure on population health (Stuckler et al., 2010). The evidence presented here contributes to this debate. The balance, for instance, between cuts to public spending and tax rises in the 1990s Swedish deficit reduction programme was $2: 1$, while in the current UK policy 
response the balance is $4: 1$ in favour of spending cuts and these cuts are taking place earlier and deeper. The consequent scale of the adverse consequences in the UK compared to the Swedish experience could be predicted to be much greater.

Cuts in public sector employment may increase the gender gap in employment rates as they did in Sweden and escalate health related exclusion from the labour market particularly for women from less skilled, manual SEGs. This has adverse consequences not just for social expenditure as these people claim disability benefits, but unemployment increases the risk of economic difficulties, social exclusion and its concomitant health effects, contributing to greater health inequalities.

Governments need to take into account the possibility of delayed and differential impacts of these policies on health and the employment prospects of people with chronic illness. Action needs to be taken to pre-empt these developments and counter their adverse effects.

\section{Acknowledgements}

This study was supported in part by grants from the Swedish Council for Working Life and Social Research and from the Nordic Council.

\section{Appendix A. Supplementary data}

Supplementary data related to this article can be found at http:// dx.doi.org/10.1016/j.socscimed.2012.09.022.

\section{References}

Beckfield, J., \& Krieger, N. (2009). Epi + demos + cracy: linking political systems and priorities to the magnitude of health inequities. Epidemiologic Review, 31, 152-177. $\mathrm{CSDH}$. (2008). Closing the gap in a generation: Health equity through action on the social determinants of health. Final Report of the Commission on Social Determinants of Health. Geneva: World Health Organization.

Dahlgren, G., \& Whitehead, M. (2007). European strategies for tackling social inequities in health: Levelling up part 2. Copenhagen: World Health Organization.

Diderichsen, F., Evans, T., \& Whitehead, M. (2001). The social basis of disparities in health. In T. Evans, M. Whitehead, F. Diderichsen, A. Bhuiya, \& M. Wirth (Eds.), Challenging inequities in health: From ethics to action. New York: Oxford University Press.

Eikemo, T., Bambra, C., Judge, K., \& Ringdal, K. (2008). Welfare state regimes and differences in self-perceived health in Europe: a multilevel analysis. Social Science E Medicine, 66(11), 2281-2295.

Esping-Andersen, G. (1990). The three worlds of welfare capitalism. Cambridge: Polity Press.
Fritzell, S., Ringbäck Weitoft, G., Fritzell, J., \& Burström, B. (2007). From macro to micro: the health of Swedish lone mothers during changing economic and social circumstances. Social Science \& Medicine, 65, 2474-2488.

HAPI. Health Action Partnership International. (2012). Working for equity in health. http://www.hapi.org.uk/what-we-do/working-for-equity-in-health.

Hetzler, A., Melén, D., \& Bjerstedt, D. (2005). Sjuk-Sverige. Försäkringskassan, reha bilitering och utslagningen från arbetsmarknaden [Sick Sweden. The Social insurance office, rehabilitation and exclusion from the labour market]. Eslöv: Brutus Östlings förlag Symposion (In Swedish).

Holland, P., Burström, B., Whitehead, M., Diderichsen, F., Dahl, E., Ng, E., et al. (2011). How do macro-level contexts and policies affect the employment chances of chronically ill and disabled people? Part I: the impact of recession and deindustrialisation. International Journal of Health Services, 41(3), 395-414.

Holland, P., Nylen, L., Thielen, K., Van den Wel, K., Chen, W. H., Barr, B., et al. (2011) How do macro-level contexts and policies affect the employment chances of chronically ill and disabled people? Part II: the impact of active and passive labour market policies. International Journal of Health Services, 41, 415-430.

Hort, S. E. O. (2009). The Swedish welfare state. a model in constant flux? In K. Schubert, S. Hegelich, \& U. Bazant (Eds.), The handbook of European welfare systems (pp. 428-443) New York: Routledge.

Lidwall, U., Bergendorff, S., Voss, M., \& Marklund, S. (2009). Long-term sickness absence: changes in risk factors and the population at risk. International Journal of Occupational Medicine and Environmental Health, 22, 157-168.

Lundberg, O. (2008). Commentary: politics and public health. International Journal of Epidemiology, 37, 1105-1108.

Lundberg, O., Åberg Yngwe, M., Kölegård Stjärne, M., Elstad, J. I., Ferrarini, T., Kangas, O., et al. (2008). The role of welfare state principles and generosity in social policy programmes for public health. Lancet, 372, 1633-1640.

Lundberg, O., Diderichsen, F., \& Åberg Yngwe, M. (2001). Changing health inequalities in a changing society? Sweden in the mid-1980s and mid-1990s. Scandinavian Journal of Public Health, 29(Suppl. 55), 31-39.

Marklund, S., \& Wikman, A. (2001). Some trends in Swedish working life in the 1990s. In S. Marklund (Ed.), Worklife and health in Sweden 2000 (pp. 7-20). Stockholm: Arbetslivsinstitutet.

Muntaner, C., Borrell, C., Ng, E., Chung, H., Espelt, A., Rodriguez-Sanz, M., et al. (2011). Review article: politics, welfare regimes, and population health. Sociology of Health and Illness, 33(6), 946-964.

Navarro, V., Muntaner, C., Borrell, C., Benach, J., Quiroga, A., Rodriguez-Sanz, M. et al. (2006). Politics and health outcomes. Lancet, 368, 1033-1037.

OECD. (2010). OECD factbook. Economic, environmental and social statistics. OECD.

Palme, J., Bergmark, Å., Bäckman, O., Estrada, F., Fritzell, J., Lundberg, O., et al. (2003). A welfare balance sheet for the 1990s. Final report of the Swedish Welfare Commission. Scandinavian Journal of Public Health, 31(Suppl. 60).

Rostila, M. (2008). The Swedish labour market in the 1990s: the very last of the healthy jobs? Scandinavian Journal of Public Health, 36(2), 126-134.

SOU 2000:83. Swedish government. Two of a kind. http://www.regeringen.se/sb/d/ $108 / \mathrm{a} / 2827$.

Statistics Sweden. (1982). Reports on Statistical Co-ordination 1982:4

Stuckler, D., Basu, S., \& McKee, M. (2010). Budget crises, health, and social welfare programmes. British Medical Journal, 341, 77-79.

Stuckler, D., Basu, S., Suhrcke, M., Coutts, A., \& McKee, M. (2009). The public health effect of economic crises and alternative policy responses in Europe. Lancet, 374, 315-323.

van der Wel, K. A., Dahl, E., \& Birkelund, G. E. (2010). Employment inequalities through busts and booms: the changing roles of health and education in Norway 1980-2005. Acta Sociologica, 53(4), 355-370.

Wikman, A. (2001). Labour market development in Sweden. In S. Marklund (Ed.) Worklife and health in Sweden 2000 (pp. 21-34). Stockholm: Arbetslivsinstitutet. 